\title{
Mean Sea Level: The Effect of the Rise in the Environment
}

\author{
Ibrahim Opeyemi Isiaka ${ }^{{ }^{*}}$, Kingsley Odinakachukwu Ndukwe ${ }^{1}$, Ufomba Samuel Chibuike ${ }^{2}$ \\ ${ }^{I}$ Department of Surveying and Geoinformatics, the Federal University of Technology, Akure, Nigeria (isiakaibroheem@gmail.com, \\ akachukwu344@gmail.com) \\ ${ }^{2}$ Department of Agricultural and Bio-Resource Engineering, the Federal University of Technology, Minna, Nigeria \\ (jacobssamue57@gmail.com). \\ *Correspondance: isiakaibroheem@gmail.com
}

\begin{abstract}
Mean sea level is a significant phenomenon in geodetic science and oceanography. The sea level has experienced an unprecedented rise recently, and this increase can be attributed to the various humaninduced activities (anthropogenic factors) ranging from deforestation to burning of fossil fuels and population increase. Several factors cause sea level rise, it has been identified that the thermal expansion of ocean water and the melting of glaciers add to the volume of water causing global sea level to rise, whereas phenomena such as ocean current, wind, pressure are responsible for the regional sea-level rise. This paper identifies climate change and global warming as the drivers of some factors causing the sea level to rise. The effect of sea-level rise has resulted in a loss of agricultural lands, destruction of transportation infrastructures, loss of lands in coastal zones and migration, and the death of some aquatic animals due to saltwater intrusion. In this paper, we reviewed several literatures published between 2017 and 2021 on -level rise and the cascading impacts of sea-level rise in various world areas. The papers reviewed borders on the mean sea level rise from different geographical areas on Earth and the monitoring of sea-level rise using different techniques. Some recommendations were also proposed for consideration.
\end{abstract}

Keywords: Mean Sea Level, Agriculture, Coastal Flooding and Transportation

Received: Oct. $18^{\text {th }}, 2021 /$ Accepted: Dec. $29^{\text {th }}, 2021$ / Online: Dec. $30^{\text {th }}, 2021$

\section{Introduction (Heading 1)}

According to Benson (2020), over the coming decades, the Intergovernmental Panel on Climate Change (IPCC) has identified sea level rise as a crucial issue facing the areas within the coastal regions in its fifth assessment report. Moreover, the most vulnerable of impact of this sea-level rise are the low-lying islands and the densely populated coastal areas; such impacts include coastal erosion, saltwater intrusion, loss of coastal wetlands, and dearth of agricultural activities due to storm surges and overflowing of the natural water bodies. From the early 20 th century, a rise of about $16-21 \mathrm{~cm}$ of the global mean sea level had been reported, with over $7 \mathrm{~cm}$ of this occurring since 1993 (Jevrejeva et al. 2016; Yi et al. 2017; Global Change Research Program 2019; Abdulateef and Naheem, 2021). There is a close relationship between the mean sea level and the Geoid. The Geoid which is the surface of equipotential that approximately coincides with the mean sea level. Thus, Geoid takes its shape from the impact of rock densities on sea level. Unlike the 2D horizontal coordinates observed while making reference toreferring the ellipsoid, the mean sea level, a function of height 
(bathymetric heights), is measured and mapped concerning the Geoid (Fubara et al., 2017). Hence, monitoring sea level is a vital task by environmental and Earth scientists.

According to Abdulateef and Naheem (2021), the global mean sea level rise could be attributed to the thermal expansion of water bodies and the melting of ice glaciers, while the regional sea level rise is due to the interplay of tides. The effects of this sea-level rise have had some negative impact on the environment which seemingly had affected the lives of man. Man and his environment are inseparable as the environment serves as that space where man and other organisms carry out their activities. If anything happens to this environment, it will have some implication on the lives of the man and other organisms. This review aims to highlight the effect of the average sea level rise and point out some recommendations. The aim was achieved by reviewing recent papers on mean sea level rise, the effect of sea level on estuaries, transportation, agriculture, and coastal wetlands loss.

\section{Methods}

In this paper, there are 28 journal articles and conference papers were collected, reviewed, selected, sorted, compiled, and analyzed to investigate the causes and the effect of sea-level rise. These selected papers were restricted to those published between 2017 and 2021. The papers were not restricted to just a specific geographical region, they spread all over different countries, and the primary source of the articles collected is Google scholar.

Table 1: Shows the List of the reviewed papers.

\begin{tabular}{ll}
\hline S/N & \multicolumn{1}{c}{ Title of Paper and Authors } \\
\hline $\mathbf{1}$ & $\begin{array}{l}\text { Coastal wetland loss, consequences, and challenges for } \\
\text { restoration by Xiuzhen Li, Richard Bellerby, Christopher Craft, } \\
\text { and Sarah E. Widney. }\end{array}$ \\
\hline $\mathbf{2}$ & $\begin{array}{l}\text { Coastal wetland adaptation to sea level rise: Quantifying the } \\
\text { potential for landward migration and coastal squeeze by Sinéad } \\
\text { M. Borchert, Michael J. Osland, Nicholas M. Enwright, Kereen } \\
\text { T. Griffith. }\end{array}$
\end{tabular}

$3 \quad$ U.S. Pacific coastal wetland resilience and vulnerability to sealevel rise by Karen Thorne, Glen MacDonald, Glenn Guntenspergen, Richard Ambrose, Kevin Buffington, Bruce Dugger, Chase Freeman, Christopher Janousek, Lauren Brown, Jordan Rosencranz, James Holmquist, John Smol, Kathryn Hargan, John Takekawa

4 Coastal Wetland Resilience, Accelerated Sea-Level Rise, and the Importance of Timescale by Torbjörn E. Törnqvist, Donald R. Cahoon, James T. Morris and John W. Day

$5 \quad$ Sea-Level Rise and Shoreline Changes Along an Open Sandy Coast: Case Study of Gulf of Taranto, Italy by Giovanni Scardino, François Sabatier, Giovanni Scicchitano, Arcangelo Piscitelli, Maurilio Milella, Antonio Vecchio, Marco Anzidei and Giuseppe Mastronuzzi

6 Sea level prediction using ARIMA, SVR and LSTM neural network: assessing the impact of ensemble Ocean-Atmospheric processes on models' accuracy by Abdul-Lateef Balogun \& Naheem

Adebisi

$7 \quad$ Coastal Structures as Beach Erosion Control and Sea Level Rise Adaptation in Malaysia: A Review by Ahmad Hadi Mohamed Rashidi, Mohamad Hidayat Jamal, Mohamad Zaki Hassan, Siti

\section{Aim of Paper}

To provide a comprehensive understanding of the importance of coastal wetlands, their current status of losses and consequences at different regions, and challenges faced for restoration

To quantify and compare the area available for landward migration of tidal saline wetlands and the area where urban development is expected to prevent migration for 39 estuaries along the wetland-rich USA Gulf of Mexico coast.

To evaluate both the vertical and horizontal response of tidal wetlands to projected changes in the rate of sea-level rise (SLR) across 14 estuaries along the Pacific coast of the continental United States.

To examine the conflicting results as to whether coastal wetlands can keep up with present-day and future sea-level rise with a focus on a timescale

To develop a submersion model of the relative sea-level rise scenario estimated for the coastal plain on the Gulf of Taranto by 2100

To integrate a broad spectrum of oceanatmospheric variables to predict sea-level variation along West Peninsular Malaysia coastline using machine learning and deep learning techniques

To review selected coastal protection structures along the shoreline of Malaysia as an erosion 
Salihah, Mohd Sendek, Syazana Lyana Mohd Sopie 1 and Mohd Radzi Abd Hamid

8 Relative Sea-Level Rise and Potential Submersion Risk for 2100 on 16 Coastal Plains of the Mediterranean Sea by Fabrizio Antonioli, Giovanni De Falco, Valeria Lo Presti, Lorenzo Moretti, Giovanni Scardino, Marco Anzidei, Davide Bonaldo, Sandro Carniel, Gabriele Leoni, Stefano Furlani, Antonella Marsico, Marcello Petitta, Giovanni Randazzo, Giovanni Scicchitano and Giuseppe Mastronuzzi

9 A Systematic Review of Civil and Environmental Infrastructures for Coastal Adaptation to Sea Level Rise by Hadi Nazarnia, Mohammad Nazarnia, Hadi Sarmasti, W. Olivia Wills

10 Assessment of Climate Change Impacts on Sea Surface Temperatures and Sea Level Rise-The Arabian Gulf by Mohamed E. Hereher

11 Investigation of transient sea level rise impacts on water quality of unconfined shallow coastal aquifers by A. Ranjbar, C. Cherubini, and A. Saber

12 Review of sea-level rise science, information and services in Bangladesh by Benjamin Harrison

13 Economy-wide effects of coastal flooding due to sea-level rise: a multi-model simultaneous treatment of mitigation, adaptation, and residual impacts by Thomas Schinko, Laurent Drouet, Zoi Vrontisi, Andries Hof, Jochen Hinkel, Junko Mochizuki, Valentina Bosetti, Kostas Fragkiadakis, Detlef van Vuuren, and Daniel Lincke

14 GPS Imaging of Global Vertical Land Motion for Studies of Sea Level Rise by William C. Hammond, Geoffrey Blewitt, Corné Kreemer, and R. Steven Nerem

15 The Impact of Sea-Level Rise on Urban Properties in Tampa Due to Climate Change by Weiwei Xie, Bo Tang, and Qingmin Meng

16 Building Capacity For Climate Adaptation Assessing the Vulnerability of Transportation Infrastructure to Sea Level Rise for Safety Enhancement in RITI Communities by Shen, Suwan and Shim, Dayea

17 Global Warming and Sea Level Rising: Impact on Agriculture and Food Security in Southern Coastal Region of Bangladesh by M. A. Awal and M. A. H. Khan

18 The impact of flooding on road transport: A depth-disruption function by Maria Pregnolato , Alistair Ford, Sean M. Wilkinson, Richard J. Dawson

19 Key factors influencing the global passenger transport dynamics using the AIM/transport model by Shivika Mittal, Hancheng Dai, Shinichiro Fujimori, Tatsuya Hanaoka, Runsen Zhang control measure and sea-level rise adaptation based on coastal management strategies.

To carry out a multidisciplinary study is to provide the first maps of sea-level rise scenarios for 2100 for the IPCC RCP 8.5 and Rahmstorf (2007) projections for the above affected coastal zones, which are the locations of touristic resorts, railways, airports and heritage sites

To present a meta-analysis and review of existing literature on the impacts of SLR on civil infrastructure.

investigates the change in the sea surface temperatures (SST) in the Gulf as a proxy to the global warming during the last 16 years

To analyse the impacts of $1 \mathrm{~m}$ gradual and instantaneous sea-level rise combined with pumping activity on seawater wedge toe location in a shallow coastal aquifer located in the southern shores of the Caspian Sea.

To provide a baseline indication of the available sea-level rise information in Bangladesh and the use of sea-level rise information for vulnerability, impact, and adaptation studies.

To present a multi-model assessment of the macroeconomic impacts of coastal flooding due to sea-level rise and the respective economy-wide implications of adaptation measures for two greenhouse gas(GHG) concentration targets, namely the Representative Concentration Pathways (RCP)2.6 and RCP4.5, and subsequent temperature increases.

To estimate the rates and patterns of vertical land motion (VLM) on all locations on Earth's land surface using GPS Imaging

To investigate parcel-level property impacts, using a specific coastal city, Tampa, Florida, USA, as an empirical study

To understand different communities' perceived travel challenges with coastal flooding, the social sensitivity to different types of challenges, and the priorities and concerns regarding the access to various types of resources, to support decision making that improves communities' safe access to highly valued resources and activities.

To analyse the effect of global warming and sealevel rise on the agriculture and food security in southern coastal areas of Bangladesh

To develop a relationship between depth of standing water and vehicle speed.

To improve the transport sector representation in AIM/CGE, by soft-linking the bottom-up type transport model, named AIM/Transport, which uses the MNL-type equation to incorporate the mitigation options related to travel behavior. 
20

Comparing impacts of climate change and mitigation on global agriculture by 2050 by Hans van Meijl, Petr Havlik, Hermann Lotze-Campen, Elke Stehfest, Peter Witzke, Ignacio Perez' Dom'inguez, Benjamin Leon Bodirsky, Michiel van Dijk, Jonathan Doelman, Thomas Fellmann, Florian Humpenoder, Jason F L Koopman, Christoph Muller, Alexander Popp, Andrzej Tabeau, Hugo Valin and Willem-Jan van Zeist

\section{1}

Demand for Ports to 2050: Climate Policy, Growing Trade and the Impacts of Sea-Level Rise by Susan E. Hanson and Robert J. Nicholls

22

Monitoring of Changes in Land Use/Land Cover in Syria from 2010 to 2018 Using Multitemporal Landsat Imagery and GIS Mohamed by Ali Mohamed, Julian Anders, and Christoph Schneider

23 Development of intertidal flats in the Dutch Wadden Sea in response to a rising sea level: Spatial differentiation and sensitivity to the rate of sea level rise by Ymkje Huismans, Ad van der Spek, Quirijn Lodder, Robert Zijlstra, Edwin Elias, Zheng Bing Wang

24 Urbanization, Climate Change And Cities: Challenges And Opportunities For Sustainable Development by Ngai Weng Chan

25 Concepts and Terminology for Sea Level: Mean, Variability and Change, Both Local and Global by Jonathan M. Gregory, Stephen M. Griffies, Chris W. Hughes, Jason A. Lowe, John A. Church, Ichiro Fukimori, Natalya Gomez, Robert E. Kopp, Felix Landerer, Gone'ri Le Cozannet, Rui M. Ponte, Detlef Stammer, Mark E. Tamisiea, Roderik S. W. van de Wal

26 Can We Model the Effect of Observed Sea Level Rise on Tides? by M. Schindelegger, J. A. M. Green, S.-B. Wilmes and I. D. Haigh

27 Assessing the Effects of Rising Groundwater from Sea Level Rise on the Service Life of Pavements in Coastal Road Infrastructure by Jayne F. Knott, Mohamed Elshaer, Jo Sias Daniel, Jennifer M. Jacobs, and Paul Kirshen

28 Sea Level Rise, Homeownership, and Residential Real Estate Markets in South Florida by Xinyu Fu \& Jan Nijman
To present a set of alternative scenarios by different models, harmonized with respect to basic model assumptions, to assess the range of potential economic impacts of climate change on the agricultural sector by 2050, as well as the economic consequences of stringent global emission mitigation efforts (e.g. bioenergy use, afforestation, reduction of methane and nitrous oxide emissions in agriculture) aiming to stabilize global warming at $2{ }^{\circ} \mathrm{C}$ by the end of the century under different SSPs.

To estimate the current and future area and costs for ports based on the handling of sea-borne freight at national and regional levels under future climate-orientated scenarios

To examine the impacts of the armed conflict in Syria, which began in mid-2011, and the related social and economic crisis on LULC between 2010 and 2018

To provide insight into how the process of drowning proceeds in time, how sensitive it is to the rate of SLR and which spatial differentiation may be expected.

This paper attempts to link climate change with sustainable cities and debate the possible solutions to address climate change and city sustainability.

To define concepts and terminology associated with sea level and sea-level changes in order to facilitate progress in sea-level science, in which communication is sometimes hindered by inconsistent and unclear language.

The study is deemed a major step toward credible predictions of secular changes in the main components of the ocean tide

To investigate the effects of groundwater rise caused by sea-level rise on the service life of pavements in coastal road infrastructure

It builds on a small but rapidly growing body of research that seeks to determine the impact of sealevel rise on the pricing of residential properties.

\section{See Level Rise}

Since the late $19^{\text {th }}$ century and the early $20^{\text {th }}$ century, the sea level has been rising due to the increase in the global temperature and researchers at NOAA have predicted that the sea level will continuously increase during the $21^{\text {st }}$ century, even at a higher rate (Lindsey, 2019; Suwan Shen and Dayea Shim, 2022). The Intergovernmental Panel on Climate Change (2007) estimated that in the $20^{\text {th }}$ century, the global sea level rose by an average of $1.7 \pm 0.5 \mathrm{~mm}$ per year. Between 1961 and 2003, Over 40 percent of the observed sea-level rise have been attributed to the warmer climate causing expansion of ocean water and the melting of ice sheets (National Research Council Ocean Studies Board, 2012; Suwan Shen and Dayea Shim, 2022). The fifth IPCC 
conservative report (Pachauri, Allen, et al., 2014; Suwan Shen and Dayea Shim, 2022) projects that by the end of this century, the Earth will experience a further sea-level rise of between $0.26 \mathrm{~m}$ and $0.82 \mathrm{~m}$. Some semiempirical models have even predicted an even higher rate of between 1m to $1.5 \mathrm{~m}$ by 2100 (Rahmstorf, 2007; Grinsted, Moore et al., 2010; Parris, Bromirski et al., 2012; Suwan Shen and Dayea Shim, 2022). Bloetscher, Romah et al. (2012) noted that by proximity, the Inhabitants of the coastal zones are at more risk of sea-level rise because of coastal erosion, saltwater intrusion, and storm surge. These zones have a high groundwater level given the soil's low holding capacity, increasing the risk of groundwater flooding (Bloetscher and Romah, 2015, Romah, 2012; Suwan Shen and Dayea Shim, 2022).

Rising sea levels can affect sustainable development such as the energy systems, transportation facilities, agricultural lands, water infrastructures, etc., in the coastal areas due to the low capacity of the soil to absorb precipitation. (Karl, Melillo et al., 2009, Zhang, 2011; Suwan Shen and Dayea Shim, 2022), Exposing coastal areas to economic and ecological vulnerabilities (Hoozemans, Marchand et al., 1993; Suwan Shen and Dayea Shim, 2022). Coastal flooding could cost 4.5 percent of the global economy of the world each year by 2200 (Desmet K. et al., 2021; Weiwei Xie et al., 2021). Flooding could be one of the most devastating natural hazards worldwide due to its ruin of human lives and properties.

Climate change has become a er of attraction as research has shown that climate conditions are changing at an accelerated rate. As one of the influences of climate change, sea-level rise has become an insistent threat to the environment and sustainable development (National Research Council, Committee on Climate Change et al., 2008; Suwan Shen and Dayea Shim, 2022). Global warming and Climate change refer to the change in the Earth weather pattern due to increasing global temperature, which has a long term effect on the earth surface, leading to the disappearing of the glaciers and ice sheets around the world, resulting in drastic changes in the Earth's climate (Oliver Smith, 2014; Weiwei Xie et al., 2021). The rate of the rise depends on future global warming and the rate of expansion and melting, rising sea increase the risk of coastal erosion, saltwater intrusion and may cause vulnerable communities to lose essential resources and services (National Research Council Ocean Studies Board, 2012; Suwan Shen and Dayea Shim, 2022). The factors affecting the regional sea-level rise are different from those of the global sea-level rise because, at a local level, ocean currents and wind are factors that pattern the sea level rise whereas, at a global scale, it is mostly thermal expansion and the melting of glaciers (Wuebbles, Fahey et al., 2017; Suwan Shen and Dayea Shim, 2022). Ocean parameters such as sea surface temperature, sea surface salinity and mean sea level pressure have been identified to be the predominant drivers of sea-level change in some regions like Willingdon Island in India (Sithara et al. 2020; Abdulateef and Naheem, 2021). On the other side, atmospheric parameters like air temperature, wind speed, cloud cover, evaporation rate play the major role in other areas like the Red Sea (Zubier and Eyouni 2020; Abdulateef and Naheem, 2021). Global sea-level rise is the most obvious manifestation of climate change in the ocean and will ultimately affect every coastal state and nation on the planet. Even a slight increase in sea level can be catastrophic to the coastal areas.

Activities causing global warming include those human-induced activities such as the felling of forest trees, bush burning, and burning fossils. However, not limited to this mention, all these activities release carbon dioxide into the atmosphere. Carbon dioxide in the atmosphere naturally helps keep the atmosphere warm, but when in excess, it causes an increase in the atmospheric temperature. The results aside, the biodiversity effects also add significantly to global warming by releasing Carbon dioxide into the atmosphere. Forest trees help to regulate the atmospheric temperature by absorbing Carbon dioxide, but when trees have been cut down to create space for various land uses they can no longer absorb Carbon dioxide and if left to decompose or burn release Carbon dioxide into the atmosphere. Also, with population increase comes the high demand of space from persons for shelter, the need to construct more roads, schools, hospitals, and more need for woods forcing deforestation. Not minding the high rate of Carbon dioxide that these humans will also release through respiration. 
Burning of fossils, Deforestation. Population Increase, Urbanization etc.

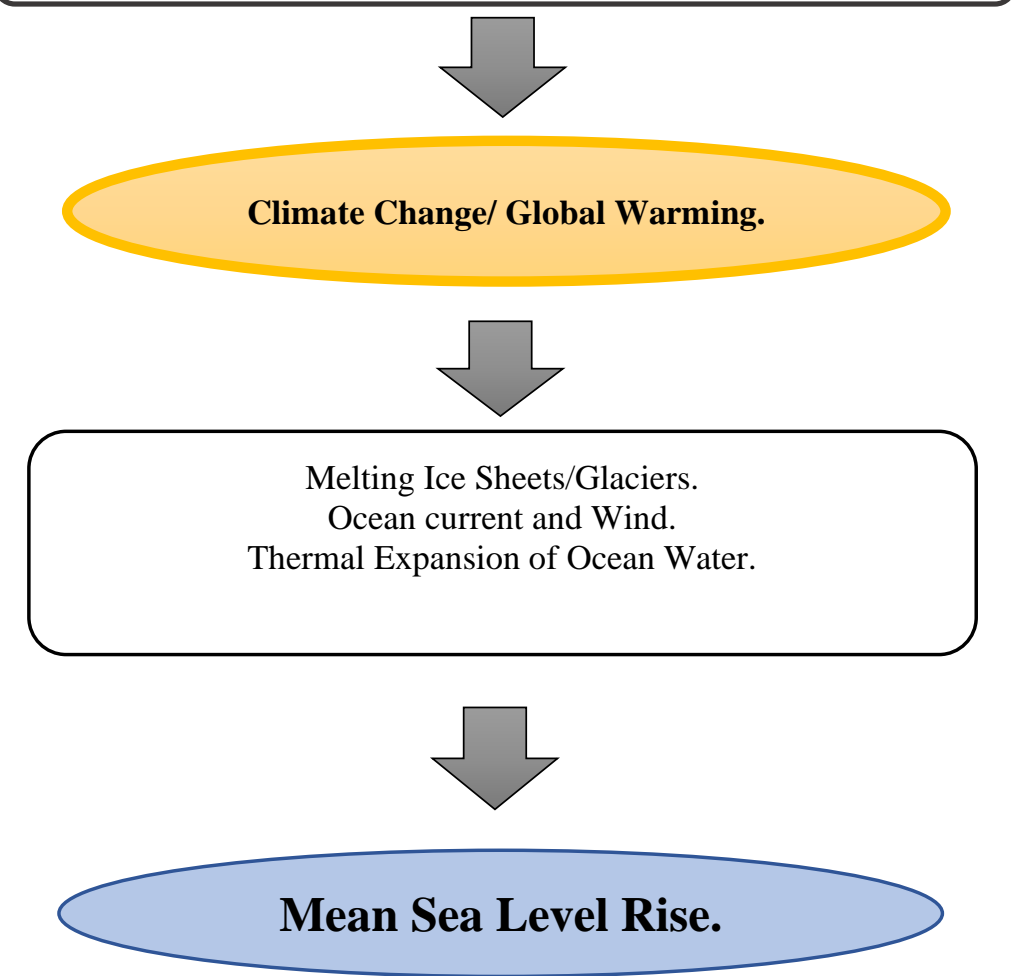

Figure 1. Some of the factors inducing Mean Sea Level Rise.

\section{Natural forests capture $\mathrm{CO}_{2}$ Deforestation releases $\mathrm{CO}_{2}$}

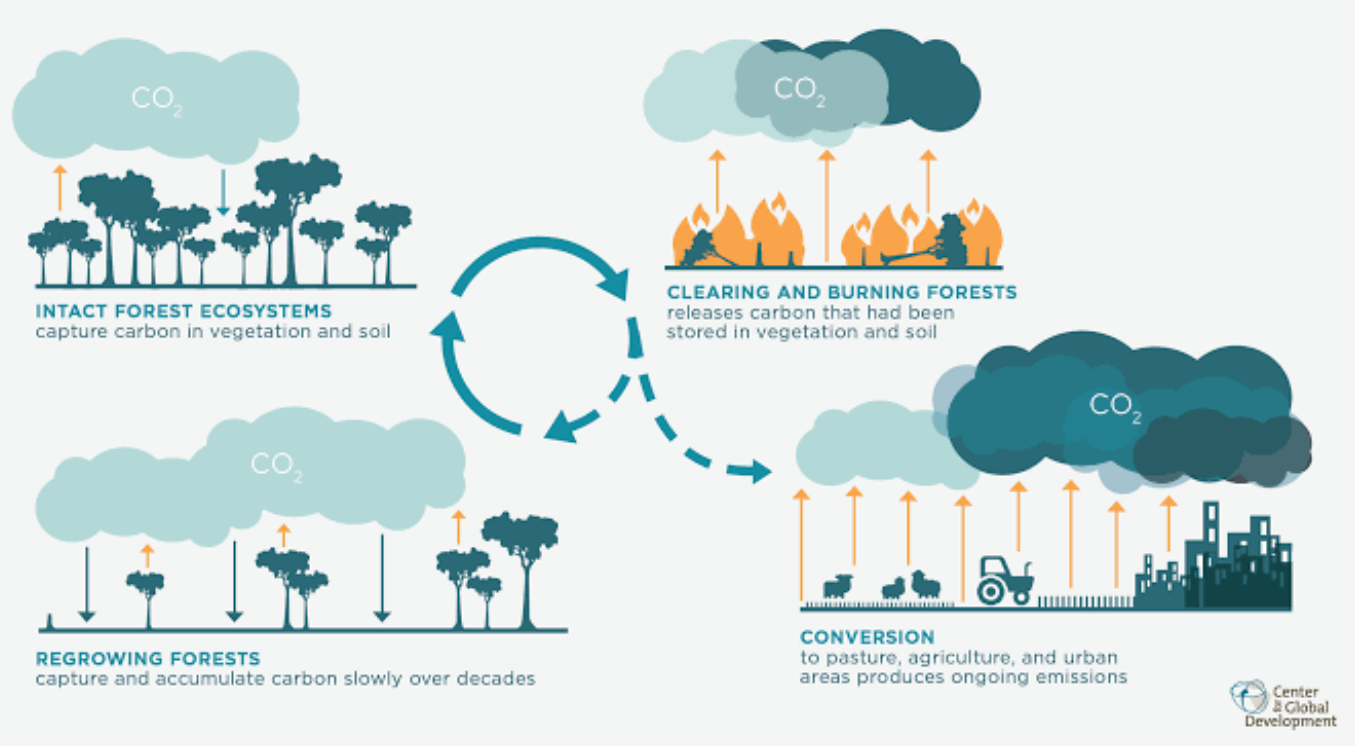

Figure 2. The processes that release carbon dioxide into the atmosphere and its interaction with the environment.

The Global warming caused by these human-induced and natural occurrences subjects the large ice land to melt and also rising temperature of the ocean causing expansion of the water body. The complexity and 
interconnected nature of the earth system mean that global warming is causing a myriad of diverse effects, with one being its effects on the melting of the ice sheets causing the sea level to rise and create a less stable and habitable environment for life. Thus to manage the mean sea level rise, it will be pertinent to address the issue of global warming as it is the bridge linking the effects of human and nature-induced factors to increased atmospheric temperature.

\section{Effects of Sea-Level Rise in the Environment}

From 1990 to 2019, the thermal expansion of seawater and melting of ice sheets and glaciers contributed to about half of the sea level rise. The average rate of sea-level rise was estimated to vary from 1.4 to $2 \mathrm{~mm}$ yr1 during the last century. Our estimation, however, is about $4 \mathrm{~mm}$ yr-1 up to the year 2090 after considering the future scenarios (Ismail et.al, 2021). This increased sea level will damage properties and shake up the biodiversity and the general ecosystem in coastal areas, with a fairly plain topography. The effects of sea level rise on the environment have been highlighted below:

\subsection{Transportation.}

Infrastructure networks are sometimes regarded as the major components that make up cities (developed, developing, or underdeveloped). In other words, transport networks have gone a long way to help improve and support the safety and wealth of communities, especially in the context of a global economy increasingly reliant on the mobility of goods, information, and people but changes in the climate has affected this transport system (Rodrigue and Notteboom, 2013; Maria Pregnolato et al, 2017). Studies have shown that climate change and the rapid development of cities, are together joining forces in putting the inbuilt environment at risk (Maria Pregnolato et al, 2017). The rise in sea level affects the transportation activities of an ecosystem, and these effects can be observed in air transport, rails, road transport, and tunnel transport as well as navigation through ships and boats.

In the aviation aspect of transportation, some areas in the world have several airports located very close to coastal areas where levees or embankment fortifications may become very difficult and costly to maintain as the climate continues to change. Therefore, runways and other structures are vulnerable to flooding when the sea level rises. This impact will cause loss of revenue to the aviation manager and might incur debt and increased costs to reconstruct the damages.

Railways often cut across wet areas in the coastal zone in rail transportation. Some railways can be so low significantly smaller short line railways, that they are prone to flooding, and the beds may be vulnerable to sinking due to peat oxidation reaction. When peat soil is exposed to oxygen, they compact, causing a vertical downward movement of the base of the rail tracks resulting in the sinking of the railways. In the case of tunnels, the hydraulic pressure of the tunnel walls increases as the water table rises as a result of sea-level rise, which subjects the tunnels to the vulnerability of flooding.

Flash flood is a problem that is peculiar to road networks, especially in urban areas where the soil surface is non-porous. Therefore, any rainfall, be it little or heavy, would cause the land to overflow water. This, as a result, would lead to drainages exceeding their capacity forcing the water to cover the roadways, making it almost impossible for vehicles to move (Maria Pregnolato et al, 2017). Recent studies have shown that roads are among the most common cause of death, especially during flooding periods, due to vehicles being driven through flooded roadways (Jonkman and Kelman, 2005; Fitzgerald et al. 2010; Maria Pregnolato et al, 2017).

Also, as the sea level rises, the groundwater is expected to rise and they will intersect in the unbound layers of coastal road infrastructure thus reducing the service life of pavements. Road surface performance is affected by parameters influenced by climate especially temperature and moisture contents of the road surface sublayer. As the sea level rise with the groundwater, they intersect the unbound layers in some locations reducing 
the road surface life span. Also, the useful life span of a pavement structure decreases with an increase in the percentage of time the unbound layers are saturated (Kont et al., 2017).

Navigation through sea/oceans, sea level rise makes water deeper, allowing deeper draft vessels to navigate a particular channel. When saltwater advances upstream, it can alter the point at which flocculation leads to sedimentation and the creation of shallows. Thus, decreasing the clearance under the bridge. This will impede the passage of boats underneath a bridge, especially when a small boat is passing underneath a very small bridge with a clearance of less than one foot. Docks, jetties, and other offshore facilities are on the water's edge, making them quite vulnerable to flooding. Though these facilities were constructed at an elevation higher than the mean sea level, they are left at suboptimal elevations with the rise in sea level.

\subsection{Salt/Sea Water Intrusion}

The major supplier of freshwater globally is groundwater and freshwater globally is of limited amount. Unfortunately, this very little amount of freshwater becomes subjected to salt/seawater intrusion (Loáiciga et al. 2012; Werner et al. 2013; Sharip et al. 2019; Ranjbar et al. 2020). Sea level rise and tidal fluctuations induced by global warming will result in increased saltwater intrusion into freshwater bodies, invariably affecting groundwater quality (Li et al. 2001; Pool et al. 2014; Sefelnasr and Sherif 2014; Kuchaksaraei et al. 2019; Ranjbar et al. 2020). Recently, some studies have shown that the predicted sea-level rise by the year 2100 will be between $0.2 \mathrm{~m}$ and $0.8 \mathrm{~m}$, which will cause extensive flooding of coastal regions (Vermeer and Rahmstorf 2009; IPCC 2013 Ranjbar et al. 2020). Ranjbar et al. 2020 had reported that Langevin and Dausman (2005) anticipated that they would be a $1.5 \mathrm{~km}$ increase in the seawater wedge toe penetration in Broward County's unconfined aquifer and $0.4 \mathrm{~km}$ saltwater intrusion in the Nile Delta's confined aquifer if the sea level increase of $0.5 \mathrm{~m}$ in Florida's coastal aquifer. Fletcher et al. (2012), investigated the saltwater intrusion of freshwater wells regarding sea-level rise on the Swedish island of Oland. They studied the area using a GIS map with $2 \mathrm{~m}$ sea level rise case study. The research focused on both the inundation of wells and saltwater intrusion into freshwater wells. Approximately 5\% of the land area and 3\% of the wells are at inundation risk which were ascertained on the generated risk map. Over $17 \%$ of the wells were categorized as being at high risk and $64 \%$ of them at medium risk, and they suggested digging new wells in low-risk zones to supply freshwater (Nazarnia et al., 2020).

A rise in sea level will allow saltwater to drop down inland and upstream in rivers posing a great danger to aquatic plants and animals, especially those intolerant to salt water and threatening human usage of the water. Salinity increment will cause a shift in salt-sensitive habitat and could thus affect the distribution of the ocean ecosystem. Saltwater intrusion will decrease water quality, thereby making it unsuitable for industrial, agricultural, drinking, and whatever purposes it is meant for.

\subsection{Agriculture}

Climate change has always had a vital role in crop and grassland yielding. When the negative impacts of rising mean sea level caused by climate change and global warming hit the agricultural land, grazing tends to become more difficult because grassland is relatively favored by climate change than crops (Havl'1k et al., 2015; Hans van Meijl et al., 2018). A $0.1 \mathrm{~m}$ to $0.5 \mathrm{~m}$ rise in sea level as predicted by most of the estimates by the middle of this century will pose a significant threat to the agriculture and livelihoods of people in low-lying coastal areas of the world (M. A. Awal and M. A. H. Khan, 2020). If this happens, we might just be edging to an era of hunger and starvation. On the issue of crop productivity, crops cultivated on relatively flat lands in coastal areas in conjunction with an increase in sea level become vulnerable to flooding and pest attacks. The flood water will wash away the crops and cause permanent inundation of such farm areas. The increase in mean sea level threatens to inundate farmlands and cause fresh groundwater to become salty in the coming decades and centuries. Aside from the fact that crop production would be drastically affected, livestock rearing and 
aquaculture would not be excluded as it now produces more seafood than wild capture fisheries (Halley E. Froehlich et al., 2018).

\section{4. Coastal Wetland Loss}

Coastal wetlands, which mainly include areas of coral reefs, salt marsh, seagrass beds, and mangroves, make up one of the most valuable ecosystems of the planet (Costanza et al., 2014; Barbier, 2019; Torbjörn et al., 2021), but the sea level rise has been a significant threat to the removal of this ecosystem. As a result of the increasing global temperature leading to thermal expansion of the oceans and melting of glaciers and ice sheets, the sea level rise is expected to accelerate (Church et al., 2013; Sweet et al., 2017; Borchert et al., 2018). Coastal wetlands are particularly defenseless to accelerated sea level rise (Scavia et al., 2002; Nicholls \& Cazenave, 2010; Kirwan \& Megonigal, 2013; Ellison, 2015; Thorne et al., 2018; Borchert et al., 2018). Coastal wetlands are highly productive in protecting human health, well-being, and the society including flood reduction, erosion control, carbon sequestration, recreational centers, reducing the effect of storm surges, and maintenance of productive coastal fisheries (Morgan, Burdick, \& Short, 2009; Barbier et al., 2011; Costanza et al., 2014; Sutton-Grier, Wowk, \& Bamford, 2015; Borchert et al., 2018). As the sea level rise accelerates, coastal wetland resources could be lost.

Over $60 \%$ of sea animals have to stay in the coastal wetlands at some point in their life cycle, and over $90 \%$ of these fisheries are harvested from the coastal zone (Hinrichsen and Olsen 1998; Xiuzhen Li et al., 2017). Mangroves and salt marshes protect the coasts and invaluable lives and treasures behind them. DahdouhGuebas et al. (2005) showed the significant difference between damage with and without mangroves after the Indian Ocean tsunami occurred in December 2014. Areas behind true mangroves were largely unaffected, while the cryptically degraded area dominated by associate species was destroyed. Villages protected by wider mangroves on the coast had significantly fewer deaths than ones with narrower or no mangroves (Das and Vincent 2009; Xiuzhen Li et al., 2017).

The loss of these wetlands will reduce the amount of harvested sea animals, low revenue and discourage going into fish farming. Sea level rise is one of the potential threats to coastal wetlands. The loss of wetlands will cause the loss of all its related ecological services for humans and society. Serious consequences of the loss of coastal wetlands include coastal flooding, erosion, economic disruption, and biodiversity decrease.

\section{Conclusions}

This paper focuses on the impact rising sea levels have had on the environment and with global warming in play, sea levels will continue to increase, thereby posing a major risk to cities, banks, hospitals, farmlands, ponds, organic landscapes, tourist destinations, beaches, and groundwater. In totality, many researchers have worked on the effects of sea-level rise and this sea-level rise has left the world with many economic and physical losses. Therefore, there is a growing need to address the issue of sea-level rise.

However, certain damages have already been inflicted on the environment, requiring humans to adapt to the situation. Also, further research should be channeled towards how to tackle the effects and develop models for better prediction of future occurrence of the disasters caused by mean sea level rise.

\section{Recommendation}

The actual effect of sea-level rise depends on what people do in response to the initial effects. With Global warming being in the center of the sea level rise. Although, some other phenomenon has been attributed to this rise, like ocean currents, groundwater removal, subsidence et cetera. Protecting people structures, road infrastructures, farmlands, ponds and property as sea level continues to rise in the years ahead will be one of the most significant engineering challenges in the coming decades. Based on the study of the effects of sealevel rise, the following recommendations were made. However, the recommendations were suggested on tackling sea level rise and include addressing the issue of global warming. 
i. Climate change education should be introduced to student' curriculum from their elementary schools.

ii. Construction of dikes and levees along coastal areas to serve as sea walls and the deformation study should be monitored at appropriate intervals using GNSS and GIS for the analysis.

iii. Artificial intelligence techniques such as Deep Learning and Machine Learning should be introduced into the study of sea level rise to better understand the trends of the data and future predictions.

iv. The present sea level and the predicted future rise should be considered when constructing buildings for residential purposes. Also, buildings/structures should always be higher than the road level to prevent draining of water from roads into building areas, thereby washing them away.

v. The emission of greenhouse gases should be guided by law to reduce their release into the atmosphere. vi. Dredging activities should be encouraged after flooding so that the organic depth of the oceans is regained for better and smooth navigation of boats.

vii. The roads should be constructed with space for a very sophisticated drainage system and waterways shouldn't be blocked.

viii. Building along waterways should be demolished and relocated to some better place.

ix. Planting of mangroves and other vegetation in areas in order to control erosion.

x. The field of data science and artificial intelligence can be used to understand the global warming data better, and note the major causes of the climate warming and thus, suitable models can be built for predicting future occurrence.

xi. GIS and other satellite data can also be used to monitor damages caused by this rise in sea level in order to manage the disaster if it has happened properly. Also, GIS can be used to analyse the area where roads, structures and lives are prone to sea-level rise effects so that immediate actions such as the evacuation of persons and properties can be taken.

xii. Authorities should monitor removal of groundwater through drilling wells or boreholes water systems.

xiii. Light detection and ranging (LIDAR) is a system that can produce high-quality topography maps. These maps are beneficial for predicting inundation in coastal regions due to SLR. The prediction could be helpful in the management policy of coastal lines.

\section{References}

A. Ranjbar, C. Cherubini \& A. Saber. (2020). Investigation of transient sea level rise impacts on water quality of unconfined shallow coastal aquifers. International Journal of Environmental Science and Technology.

Abdul-Lateef B. \& Naheem A. (2021). Sea level prediction using ARIMA, SVR and LSTM neural network: assessing the impact of ensemble Ocean-Atmospheric processes on models' accuracy. Taylor \& Francis: Geomatics, Natural Hazards and Risk, 12(1), 653-674.

Ahmad H. M., Mohamad H. J., Mohamad Z. H., Siti S. M., Syazana L. M. \& Mohd R. A. (2021). Coastal structures as beach erosion control and sea level rise adaptation in Malaysia: A Review. Water, 13(1741), 1-34.

Benjamin H. (2020). Review of sea-level rise science, information and services in Bangladesh. (Unpublished).

Dagogo M. J. F., Francis A. F. \& Christian U. E. (2017). Fundamentals of geodesy. Concept publications limited, ISBN 978978-52562-1-5.

Fabrizio A., Giovanni D. F., Valeria Lo P., Lorenzo M., Giovanni S., Marco A., Davide B., Sandro C., Gabriele L., Stefano F., Antonella M., Marcello P., Giovanni R., Giovanni S. \& Giuseppe M. (2020). Relative sea-level rise and potential submersion risk for 2100 on 16 coastal plains of the Mediterranean Sea. Water, 12(2173), 1-25, DOI: 10.3390/w12082173.

Giovanni S., François S., Giovanni S., Arcangelo P., Maurilio M., Antonio V., Marco A. \& Giuseppe M. (2020). Sea-level rise and shoreline changes along an open sandy coast: case study of gulf of Taranto, Italy. Water, 12(1414), $\quad 1-22, \quad$ DOI: $10.3390 / \mathrm{w} 12051414$.

Hadi N., Mohammad N., Hadi S. \& Olivia W. W. (2020). A systematic review of civil and environmental infrastructures for coastal adaptation to sea level rise. Civil engineering journal, 6(7), 1375-1399.

Hans V., Petr H., Hermann L., Elke S., Peter W., Ignacio P. D., Benjamin L. B., Michiel D., Jonathan D., Thomas F., Florian H., Jason F. L. K., Christoph M., Alexander P., Andrzej T., Hugo V. \& Willem-Jan V. (2018). Comparing impacts of climate change and mitigation on global agriculture by 2050. Environmental research letters, 13(2018), 064021. 
Jayne F. K., Mohamed E., Jo S. D., Jennifer M. J. \& Paul K. (2017). Assessing the effects of rising groundwater from sea level rise on the service life of pavements in coastal road infrastructure. Transportation Research Record: Journal of the Transportation Research Board, 2639, 1-10.

Jonathan M., Stephen M., Chris W., Jason A., John A., Ichiro F., Natalya G., Robert E., Felix L., Gone'ri Le C., Rui M., Detlef S., Mark E. \& Roderik S. (2019). Concepts and terminology for sea level: mean, variability and change, both local and global. Surveys in geophysics, DOI: 10.1007/s10712-019-09525-Z.

Karen T., Glen M., Glenn G., Richard A., Kevin B., Bruce D., Chase F., Christopher J., Lauren B., Jordan R., James H., John S., Kathryn H., John T. (2018). U.S. Pacific coastal wetland resilience and vulnerability to sea-level rise. SCIENCE ADVANCES, 4(2), 1-10, DOI: 10.1126/sciadv.aao3270.

M. A. Awal \& M. A. H. Khan. (2020). Global warming and sea level rising: impact on agriculture and food security in southern coastal region of Bangladesh. Asian Journal of Geographical Research, 3(3), 9-36.

Maria P., Alistair F., Sean M. W. \& Richard J. D. (2017). The impact of flooding on road transport: A depth-disruption function. Elsevier: Transportation Research Part D 55 (2017) 67-81.

Mohamed A. M., Julian A. \& Christoph S. (2020). Monitoring of changes in land use/land cover in Syria from 2010 to 2018 using multitemporal Landsat imagery and GIS. Land, 9(226), 1-30, DOI: 10.3390/land9070226.

Mohamed E. H. (2020). Assessment of climate change impacts on sea surface temperatures and sea level rise-The Arabian Gulf. Climate, 8(50), 1-14, DOI: 10.3390/cli8040050.

Ngai W. C. Urbanization, climate change and cities: challenges and opportunities for sustainable development. Conference presentation at the Asia-Pacific Chemical, Biological \& Environmental Engineering Society (APCBEES) International Conference, January $21^{\text {st, }}$ 2017, 1 - 11.

Schindelegger M., Green J. A. M., Wilmes S. B., \& Haigh I. D. (2018). Can we model the effect of observed sea level rise on tides?. Journal of geophysical research: Ocean, 4594-4609, DOI: 10.1029/2018JC013959.

Shen S. \& Shim D. (2022). Building capacity for climate adaptation: assessing the vulnerability of transportation infrastructure to sea level rise for safety enhancement in RITI communities. University of Alaska. 1-58.

Shivika M., Hancheng D., Shinichiro F., Tatsuya H., Runsen Z. (2017). Key factors influencing the global passenger transport dynamics using the AIM/transport model. Elsevier: Transportation Research Part D 55 (2017) 373-388.

Sinéad M. B., Michael J. O., Nicholas M. E. \& Kereen T. G. (2018). Coastal wetland adaptation to sea level rise: Quantifying potential for landward migration and coastal squeeze. Journal of applied ecology, 55, 2876- $\quad 2887, \quad$ DOI: 10.1111/1365-2664.13169.

Susan E. H. \& Robert J. N. (2020). Demand for ports to 2050: climate policy, growing trade and the impacts of sea- level rise. Earth's Future, 1-13, DOI: 10.1029/2020EF001543.

Thomas S., Laurent D., Zoi V., Andries H., Jochen H., Junko M., Valentina B., Kostas F., Detlef V. \& Daniel L. (2020). Economywide effects of coastal flooding due to sea level rise: a multi-model simultaneous treatment of mitigation, adaptation, and residual impacts. Environmental Research Communications, 2, 1-15, 015002.

Torbjörn E. T., Donald R. C., James T. M. \& John W. D. (2021). Coastal wetland resilience, accelerated sea-level rise, and the importance of timescale. AGU Advances, 1-9, DOI: 10.1029/2020AV000334.

Weiwei X., Bo T. \& Qingmin M. (2021). The impact of sea-level rise on urban properties in Tampa due to climate change. Water, 14(13), 1-13.

William C. H., Geoffrey B., Corné K. \& Steven R. N. (2021). GPS imaging of global vertical land motion for studies of sea level rise. Journal of Geophysical Research: Solid Earth, 1-26, DOI: 10.1029/2021JB022355.

Xinyu F. \& Jan N. (2020). Sea level rise, homeownership, and residential real estate markets in South Florida. The Professional Geographer, 73(1), 62-71, DOI: 10.1080/00330124.2020.1818586.

Xiuzhen L., Richard B., Christopher C. \& Sarah E. W. (2018). Coastal wetland loss, consequences, and challenges for restoration. Canadian Science Publishing: Anthropocene Coasts, 1(2018), 1-15.

Ymkje H., Ad V., Quirijn L., Robert Z., Edwin E., Zheng B. W. (2021). Development of intertidal flats in the Dutch Wadden Sea in response to a rising sea level: Spatial differentiation and sensitivity to the rate of sea level rise. Elsevier: Ocean and Coastal Management, 216 (2022), 1-11, 105969. 